\title{
Study of the operating modes of a microwave installation for heat treatment and disinfection of grain
}

\author{
Vladimir Storchevoy ${ }^{1, *}$, Sergey Suchugov ${ }^{1}$, Peter Umansky ${ }^{1}$, and Alexander Storchevoy ${ }^{1}$ \\ ${ }^{1}$ Russian State Agrarian University - Moscow Agricultural Academy named after K.A. Timiryazeva, \\ 49, st. Timiryazevskaya, 127550, Moscow, Russia
}

\begin{abstract}
Calculation method has been developed and mathematical models of the main parameters and operating modes of microwave installations for disinfecting grain and ensuring the required temperature regime, the rate of grain heating by controlling the temperature have been obtained. The use of microwave installations improves the process of grain disinfection from pathogenic microflora and pests. Microwave technologies and installations for grain disinfection include a number of operations that allow grain to be disinfected up to $75-85 \%$ of living pests that do not allow grain to be stored for a long time. Therefore, for agricultural enterprises, improving the parameters and modes of microwave operation for disinfecting grain is very important. In this regard, we propose a method for calculating the parameters and operating modes of microwave installations for disinfecting grain and ensuring the required temperature regime, the rate of grain heating by regulating the temperature. The choice of the power of microwave installations, the field strength and the working part of the capacitor is closely related to the fulfillment of the requirements for microwave installations for grain disinfection.
\end{abstract}

\section{Introduction}

Studies carried out by a number of authors on grain disinfection and ensuring the required temperature regime in the design and manufacture of microwave installations [1, $11,13]$ have shown the need to obtain the required temperature and the regime of thermomechanical action on grain and the design features of the microwave installation, which should provide the required temperature regime, grain heating rate, grain preservation and quality. The choice of the power of microwave installations, field strength and the working part of the capacitor is closely related to the fulfillment of the requirements for microwave installations for grain disinfection. The main tasks of the study of this problem include: obtaining mathematical models of the process, which describe the relationship between the variable parameters of the technological process with the criteria for assessing the effectiveness of the process; determination of the parameters of the microwave installation by temperature.

\footnotetext{
*Corresponding author: V_Storchevoy@mail.ru
} 


\section{Materials and Methods}

The determination of the main parameters of the microwave installation and its operation modes was carried out on the basis of mathematical models describing the working processes of exposure to feed grain in an entolerator using an electromagnetic field of ultrahigh frequency. The design of the units of the microwave installation for grain disinfection was carried out using the applied computer programs KOMPAS-3D V13. The rational operating modes of the microwave installation for disinfecting grain from pathogenic microflora and pests were determined using the applied computer programs "Statisic V10.0". Our experimental studies, at the laboratory stand "Electrotechnological installations and systems" at the Russian State Agrarian University - Moscow Agricultural Academy named after K.A. Timiryazev in 2020, made it possible to determine the dependence of the temperature on the operating time of the microwave installation for temperature control according to Pi PID laws, and to select the most effective modes of temperature control in the microwave installation.

\section{Results}

In the process of a theoretical study of the thermomechanical destruction of grain in an entolerator using the microwave electromagnetic field, it is necessary to include the development and study of mathematical models of the process that describe the relationship between the variable parameters of the technological process with the criteria for evaluating the effectiveness of the process. As a result of statistical processing of experimental data, regression equations were obtained that describe the process of thermomechanical destruction of feed grain. For these purposes, a matrix for planning a three factorial experiment of the type $2^{3}$ (Table 1 ).

Table 1. Active experiment planning type matrix $2^{3}$.

\begin{tabular}{|c|c|c|c|c|c|c|c|c|}
\hline \multirow[b]{2}{*}{ № } & \multicolumn{3}{|c|}{ Variable parameters } & \multicolumn{5}{|c|}{ Optimization criteria } \\
\hline & 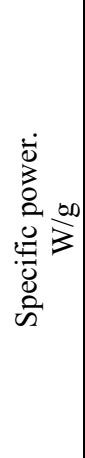 & 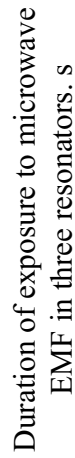 & 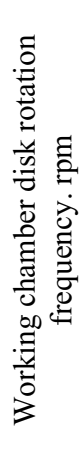 & 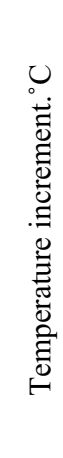 & 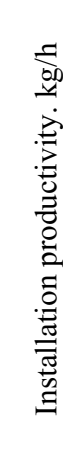 & 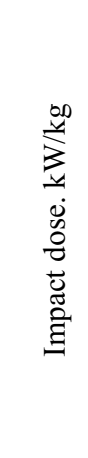 & 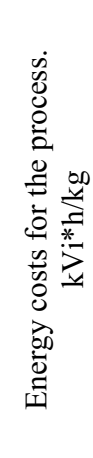 & 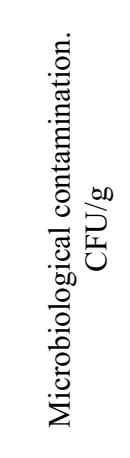 \\
\hline & $\mathrm{P}_{s p}$ & $\tau$ & $\mathrm{n}$ & $\begin{array}{c}Y_{1} \\
\Delta \mathrm{T}\end{array}$ & $\begin{array}{l}Y_{2} \\
\mathrm{Q}\end{array}$ & $\begin{array}{l}Y_{3} \\
\mathrm{D}\end{array}$ & $\begin{array}{l}Y_{4} \\
\mathrm{~W}\end{array}$ & $\begin{array}{l}Y_{5} \\
\mathrm{C}\end{array}$ \\
\hline 1 & 2 & 250 & 50 & 50 & 40 & 0.145 & 0.146 & 600000 \\
\hline 2 & 2 & 175 & 100 & 30 & 60 & 0.1 & 0.031 & 700000 \\
\hline 3 & 2 & 100 & 150 & 17 & 100 & 0.058 & 0.05 & 1000000 \\
\hline 4 & 5 & 250 & 100 & 46 & 17 & 0.34 & 0.092 & 250000 \\
\hline
\end{tabular}




\begin{tabular}{|c|c|c|c|c|c|c|c|c|}
\hline 5 & 5 & 175 & 150 & 55 & 25 & 0.23 & 0.06 & 300000 \\
\hline 6 & 5 & 100 & 100 & 27 & 43 & 0.132 & 0.031 & 900000 \\
\hline 7 & 8 & 250 & 150 & 90 & 10 & 0.58 & 0.184 & 200000 \\
\hline 8 & 8 & 175 & 100 & 80 & 15 & 0.39 & 0.123 & 200000 \\
\hline 9 & 8 & 100 & 50 & 50 & 25 & 0.23 & 0.061 & 600000 \\
\hline
\end{tabular}

The following were chosen as the main factors influencing the process of heat treatment of non-food raw materials: specific power of the microwave generator $\left(x_{1}\right) \mathrm{W} / \mathrm{g}$; duration of exposure to EMF microwave $\left(x_{2}\right) s$; working chamber disk rotation frequency $\left(x_{3}\right) \mathrm{rpm}$ When choosing the intervals for changing the factors, two main factors are guided - these are the technological conditions of the process of thermomechanical action on grain and the design features of the microwave installation. The choice of the intervals for changing the factors is conditioned by the technological conditions and design parameters of the microwave installation. The main criteria that affect the process of thermomechanical action on grain are: $Y_{1}$ - temperature increment $\Delta T$, which allows you to determine to what extent the grain is heated, ${ }^{\circ} \mathrm{C} ; Y_{2}-$ microwave entolerator performance $\mathrm{Q}$, which is one of the main characteristics of the microwave installation, $\mathrm{kg} / \mathrm{h} ; Y_{3}-$ exposure dose $\mathrm{D}$ determines the degree of exposure to microwave EMF on grain, $\mathrm{kW} * \mathrm{~h} / \mathrm{kg} ; Y_{4}-$ specific energy costs $\mathrm{W}$, used to determine the energy consumption of the disinfection process, $\mathrm{kW} * \mathrm{~h} / \mathrm{kg} ; Y_{5}-$ microbiological contamination of TMP, showing the degree of disinfection of the grain mass, $\mathrm{CFU} / \mathrm{g}$. All factors were compatible and not correlated with each other. As a result, two-dimensional sections and surfaces of responses were determined in the Statisic V10.0 program (Fig. 1.)

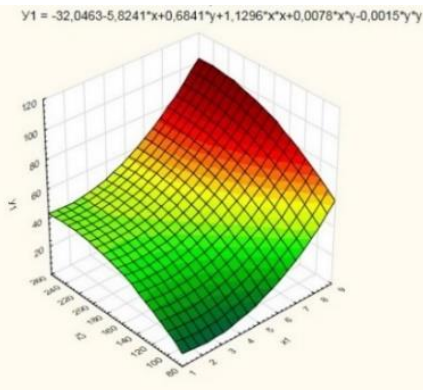

a) Surface plots for $\mathrm{Y} 1$ and $\mathrm{X} 1$ and $\mathrm{X} 2$

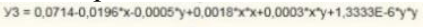

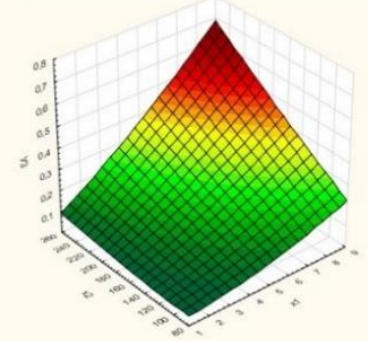

c) Surface plots for $\mathrm{Y} 3$ and $\mathrm{X} 1$ and $\mathrm{X} 2$

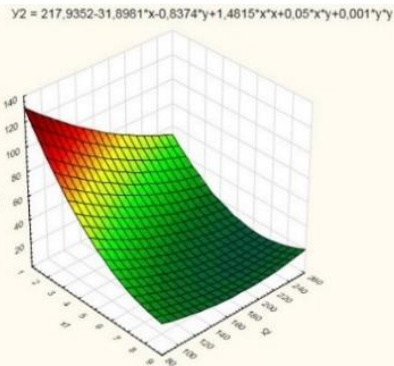

b) Surface plots for $\mathrm{Y} 2$ and $\mathrm{X} 1$ and $\mathrm{X} 2$

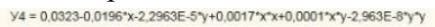

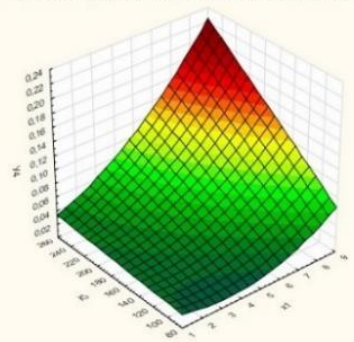

d) Surface plots for Y4 and X1 and X2 


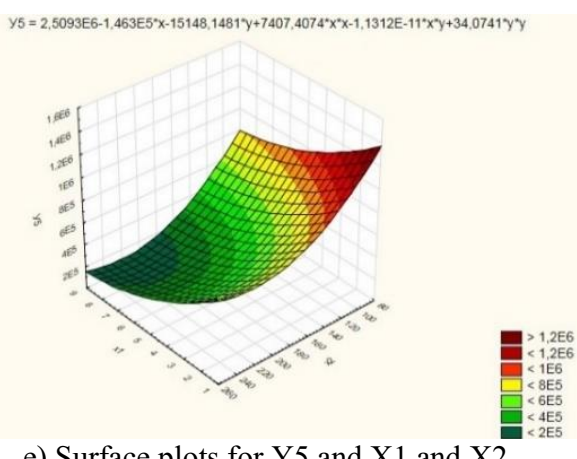

Fig. 1. 2D sections and response surfaces in Statisic V10.0 software.

Where:

a) temperature increment in a microwave entolerator at disk rotation frequency of 100 rpm;

b) productivity of the installation in a microwave entolerator at disk rotation frequency of $100 \mathrm{rpm}$;

c) exposure dose in microwave entolerator at working chamber disk rotation frequency of $100 \mathrm{rpm}$;

d) energy consumption in microwave entolerator at working chamber disk rotation frequency of $100 \mathrm{rpm}$;

e) microbiological contamination of the model in microwave entolerator at rotational speed of the working chamber disk of $100 \mathrm{rpm}$.

Regression models (1) and effective modes of thermomechanical impact on feed grain, as well as empirical expressions for each of the optimization criteria were obtained:

$$
\begin{gathered}
\mathrm{Z}_{1}=-32,0463-5,8241 * \mathrm{x}+0,6841 * \mathrm{y}+1,1296 * \mathrm{x} * \mathrm{x}+0,0078 * \mathrm{x} * \mathrm{y}- \\
-0,0015 * \mathrm{y} * \mathrm{y} \\
\mathrm{Z}_{2}=217,9352-31,8981 * \mathrm{x}-0,8374 * \mathrm{y}+1,4815 * \mathrm{x} * \mathrm{x}+0,05 \\
* \mathrm{x} * \mathrm{y}+0,0011 * \mathrm{y} * \mathrm{y} \\
\mathrm{Z}_{3}=0,0714-0,0196 * \mathrm{x}-0,0005 * \mathrm{x}+0,0018 * \mathrm{x} * \mathrm{x}+0,0003 \\
* \mathrm{x} * \mathrm{y}+1,333 \mathrm{E}-6 * \mathrm{y} * \mathrm{y} \\
\mathrm{Z}_{4}=0,0323-0,0196 * \mathrm{x}-2,2963 \mathrm{E}-5 * \mathrm{y}+0,0017 * \mathrm{x} * \mathrm{x}+0,0001 \\
* \mathrm{x} * \mathrm{y}-2,963 \mathrm{E}-8 * \mathrm{y} * \mathrm{y} \\
\mathrm{Z}_{5}=2,5093 \mathrm{E}-6-1,463 \mathrm{E} 5 * \mathrm{x}-1514,1481 * \mathrm{y}+7407,4074 * \mathrm{x} * \\
\mathrm{x}-1,1312 \mathrm{E}-11 * \mathrm{x} * \mathrm{y}+34,0741 * \mathrm{y} * \mathrm{y}
\end{gathered}
$$

Thus, we obtained regression models (2) and effective modes of grain processing in a microwave installation: 


$$
\begin{gathered}
\begin{array}{r}
\Delta T=-32,0463-5,8241 * x+0,6841 * y+1,1296 * x * x+0,0078 * \\
* x * y-0,0015 * y * y
\end{array} \\
Q=217,9352-31,8981 * x-0,8374 * y+1,4815 * x * x+0,05 * \\
* x * y+0,0011 * y * y \\
D=0,0714-0,0196 * x-0,0005 * x+0,0018 * x * x+0.0003 * \\
* x * y+1333 E-6 * y * y \\
W=0,0323-0,0196 * x-2,2963 E-5 * y+0,0017 * x * x+0,0001 * \\
* x * y-2,963 E-8 * y * y \\
\mathrm{C}=2,5093 E-6-1,463 E 5 * x-1514,1481 * y+7407,4074 * x * x- \\
-1,1312 \mathrm{E}-11-11 * \mathrm{x} * \mathrm{y}+34,0741 * \mathrm{y} * \mathrm{y}
\end{gathered}
$$

where, $\Delta T$ - temperature increment, ${ }^{\circ} \mathrm{C}$

$Q$ - plant productivity, $\mathrm{kg} / \mathrm{h}$

$D$ - exposure dose, $\mathrm{kW} / \mathrm{kg}$

$W$ - energy costs for the process, $\mathrm{kW}^{*} \mathrm{~h} / \mathrm{kg}$

$\mathrm{C}$ - microbiological contamination, $\mathrm{CFU} / \mathrm{g}$

Our experimental studies, at the laboratory stand "Electrotechnological installations and systems", made it possible to determine the dependence of the temperature on the operating time of the microwave installation according to the P and PID laws. PID control is more effective, because when using this control, as the required temperature is reached, it implies a decrease in power. Typically PID controls are chosen to reduce noise and lag. When using the PID law, the plot is described by the following equation 3 :

$$
u(t)=P+I+D=K_{p} e(t)+K_{i} \int_{0}^{t} e(\tau) d \tau+K_{d} \frac{d e}{d t}
$$

where, $K_{p}, K_{i}, K_{d}$ - the gains of the proportional, integrating and differentiating components of the controller, respectively.

\section{Discussion}

As a result of our research, and taking into account the research of a number of authors cited above, it is necessary to use the assumptions and requirements for the design, manufacture and operation of microwave installations for disinfecting grain and ensuring the required temperature regime: ensuring the required temperature regime, grain heating rate; preservation and quality of grain; compliance of the parameters of electrical loads with the parameters of the power source; the maximum value of the efficiency of the microwave installation. The choice of the power of microwave installations, field strength and the working part of the capacitor is closely related to the fulfillment of the requirements for microwave installations for grain disinfection. So the power of microwave installations for disinfecting grain is called the useful nominal power, which is determined by the formulas for thermal calculation. Thermal calculation of microwave units for grain disinfection is based on the joint solution of the equations of heat balance and heat transfer taking into account the dynamics of heating. The power and main design dimensions of microwave installations for disinfecting grain with dielectric heating are determined knowing the initial data of microwave installations for disinfecting grain with dielectric heating. These include technological conditions: the purpose of the installation, the amount of heated material $\mathrm{M}$ 
$(\mathrm{kg})$ or productivity $\mathrm{G}(\mathrm{kg} / \mathrm{h})$, the electrical and thermophysical characteristics of the material, the time $\tau(\mathrm{s})$ or the rate $\mathrm{dt} / \mathrm{d} \tau\left({ }^{\circ} \mathrm{C} / \mathrm{s}\right)$ of heating, initial $\mathrm{t} 1$ and final $\mathrm{t} 2\left({ }^{\circ} \mathrm{C}\right)$ heating temperature, ambient temperature t0, etc. We propose to use a TC4-S thermostat for automatic temperature control in a microwave installation, developed by Autonics. The use of this thermostat will allow automating the heating process, the sensor will automatically turn on the installation to heat up to the set temperature and turn it off when this temperature is reached, which will reduce the energy consumption of the installation. Temperature control in the TC4-S sensor is carried out thanks to the PID control algorithm, which in combination with a short temperature measurement interval of about $100 \mathrm{~ms}$, allows achieving an accuracy of $0.1^{\circ} \mathrm{C}$. The controller has 2 outputs that control switching: the first $12 \mathrm{~V}$ output, which supplies control voltage to the solid state relay for non-contact switching, and the traditional contact executive relay output. PID control devices are most popular for maintaining a set temperature level. The P-law is one of the special cases of the PID-law, when only the proportional component is taken into account in the regulation process.

\section{Conclusion}

As a result of the research, we obtained mathematical models and the required modes of grain processing in the processing chamber (1), which reduce the specific energy costs for drying grain and microbiological contamination of grain. Effective operating modes were obtained (2): the mass of a one-time grain loading into the resonator is $75 \mathrm{~kg}$, the temperature duration of exposure to the grain is $175 \mathrm{~s}$. As a result, microbial contamination is reduced from 3 million to 0.3 million CFU / g; at a heating temperature of $44{ }^{\circ} \mathrm{C}$, the plant productivity is $25 \mathrm{~kg} / \mathrm{h}$. Ensuring the required temperature regime, the rate of grain heating by regulating the temperature according to the P and PID laws, by using the TC4-S controller, allows you to improve the electrical technology of the grain disinfection process, maintain grain quality and reduce operating costs. It was found that with PID control, the process is smoother and maintaining the temperature with PID control is more accurate, which makes it possible to reduce the measurement error and avoid possible overheating of the grain.

\section{References}

1. A.A. Belov, M.V. Belova, G.V. Novikova et al., Estestv. Tekh. Nauki 1, 121-123 (2015)

2. M.V. Belova, Vestn. Kazan. Gos. Agrarn. Univ. 4, 31-37 (2015)

3. G.V. Novikova, G.V. Zhdankin, O.V. Mikhailova, A.A. Belov, Vestn. Kazan. Gos. Agrarn. Univ. 4, 89-93 (2016)

4. G.V. Zhdankin, G.V. Novikova, B.G. Ziganshin, Vestn. Izhevsk. Gos. S-kh. Akad. 1, 61-69 (2017)

5. G.V. Zhdankin, B.G. Ziganshin, M.V. Belova, Vestn. Kazan. Gos. Agrarn. Univ. 4, 79-83 (2016)

6. G.V. Zhdankin, V.F. Storchevoi, B.G. Ziganshin, G.V. Novikova, Nauchn. Zhizn. 4, 4-14 (2017)

7. G.V. Zhdankin, V.F. Storchevoi, G.V. Novikova, RF Patent 2671712 (2018)

8. A.N. Vasiliev, D.A. Budnikov, N.N. Gracheva, A.A. Smirnov, Handbook of Research on Renewable Energy and Electric Resourcesfor Sustainable Rural Development (IGI Global, USA, PA, Hershey, 2018) DOI: 10.4018/978- 1- 5225- 3867- 7.ch011 
9. D.A. Budnikov, A.N. Vasiliev, Handbook of Research on Renewable Energy and Electric Resourcesfor Sustainable Rural Development (IGI Global, USA, PA, Hershey, 2018) DOI: 10.4018/978-1-5225-3867-7.ch020

10. D.A. Budnikov, A.N. Vasiliev, ICO 2018: Intelligent Computing \& Optimization 866, 139-145 (2019) DOI: 10.1007/978-3-030-00979-3_14

11. G.V. Zhdankin, O.V. Mikhailova, V.G Semenov, National academy of sciences of the republic of Kazakhstan (Series of geology and technical sciences) 2(428), 44-54 (2018)

12. D.A. Budnikov, A.N. Vasilyev, D.A. Tikhomirov, A.A. Vasilyev, Springer Innovations in Communication and Computing 115, 69-70 (2019) https://doi.org/10.1007/978-3030-03898-4

13. V.F. Storchevoy, G.V. Zhdankina, G.V. Novikovaa, P.M. Umanskya, Russian Agricultural Sciences 46(1), 94-99 (2020)

14. A.N. Vasiliev, V.P. Goryachkina, D. Budnikov, International Journal of Energy Optimization and Engineering (IJEOE) 9(2), 11 (2020) DOI: 10.4018/IJEOE.2020040101

15. D. Budnikov, A.N. Vasilyev, Advances in Intelligent Sys-tems and Computing 1072, 93-100 (2020) 